\title{
PENGADAAN POMPA AIR BERDAYA 4KW UNTUK PENAMBAH DEBIT AIR DI DAERAH PERSAWAHAN SAWAH BALONG
}

\author{
Yandi Kurniawan ${ }^{1}$, Delta Prayoga Nugraha ${ }^{2}$, Awan Wahyu Setiawan ${ }^{3}$ \\ ${ }^{1,2,3}$ Prodi D3- Teknik Elektronika Jurusan Teknik Elektro, Politeknik Negeri Bandung \\ Email: yandi.kurniawan.tele18@polban.ac.id
}

ABSTRAK

Daerah persawahan sawah balong sering mengalami penurunan debit air pada musim kemarau sehingga petani harus melakukan giliran dalam mengairi sawahnya sehingga menimbulkan potensi konflik sosial. Tujuan dari penelitian ini adalah merancang sistem pompa air 4 KWdan memberikan solusi atas permasalahan petani yang berada pa daerah persawahan sawah balong. Manfaat dari penelitian ini meredakan konflik sosial yang disebabkan oleh penggantian pembukaan air untuk sawah karena debit air yang kecil pada irigasi sawah dan menumbuhkan pertanian yang lebih produktif. Metode yang digunakan adalah studi pustaka dan observasi. Untuk penyelesaian masalahnya pertama mencari sumber air baru yang dekat dengan persawahan tersebut kemudian merancang sistm pompa yang akan menyedot air kemudian mengalirakanya dan menentukan sumber daya yang akan digunakan. Pengadaan pompa dapat menjadi solusi atas permasalahan menurunnya debit air pada musim kemarau di daerah persawahan sawah balong.

Kata Kunci : debit,sawah,pompa, mikrohidro,solar panel,4KW

\section{ABSTRACT}

Sawah balong rice field, oftenly have a decrease amount of water in the dry season, so the farmers have to do some queue so its rice field can have some water supply, this condition cause a conflict between the farmers, the goals of this research is to design a $4 \mathrm{~kW}$ water pump driver to give the farmers of the sawah balong the solution for the problem because of the queue for the water irrigation because of the low amount of water supply for the rice field, in the other hand this research make the farmers of the sawah balong be more productive. The method that being use is study literature and observation. To solve the problem first we have to search for water source alternatives that located near the region of sawah balong, then design a waterpump system to irrigate the water source that has been find, the procurement of this waterpump can be a solution for the decrease amount of water that irrigate the sawah balong in the dry season

Keyword: debit,fields,pump, microhidro, solar panel, $4 \mathrm{KW}$ 


\section{Pendahuluan}

a. Latar Belakang

Desa Situraja Utara merupakan salah satu Desa di kecamatan Situraja yang ada di Kabupaten Sumedang. Desa Situraja Utara memiliki luas wilayah sekitar $2,7 \mathrm{~km}^{2}$ dengan jumlah penduduk 4480 jiwa. Mata pencaharian penduduk Desa Situraja Utara didominasi oleh petani maupun buruh tani. Secara topografi Desa Situraja Utara memiliki bentuk permukaan tanah berupa perbukitan yang berada di ketinggian $331 \mathrm{~m}$ di atas permukaan laut.

Pada musim kemarau debit air yang dikirim dari daerah Cibungur sering kali menurun sehingga para petani harus melakukan pembagian giliran untuk mengairi sawah. Dengan mekanisme setiap petani yang mendapatkan giliran harus menyumbat air tiap sawah yang ada. Hal itu sangat menyulitkan petani. Seringkali terjadi konflik antar petani disebabkan oleh mereka yang memperebutkan giliran dengan alasan sawahnya sudah kering. Itu merupakan masalah yang sering terjadi dia daerah persawahan Sawah Balong. Di daerah tersebut juga sangat didominasi dengan daerah persawahan sehingga pembuatan sumur untuk membantu pengairan sangat sulit. Dengan adanya pompa air untuk mengalirkan air ke sawah dari daerah sumber air, petani tidak perlu melakukan giliran saat mengairi sawahnya. Dengan adanya pompa air ini diharapkan dapat meningkatkan produktivitas sawah di situraja dan dapat memperbaiki hubungan sosial antara petani.

Pompa adalah perangkat yang memindahkan fluida (cairan atau gas), atau terkadang bubur, dengan tindakan mekanis, biasanya diubah dari energi listrik menjadi energi hidraulik. Pompa dapat diklasifikasikan menjadi tiga kelompok besar menurut metode yang mereka gunakan untuk memindahkan fluida: pompa angkat langsung, perpindahan, dan gravitasi. ( P.L. Fraenkel , 1986)

Oleh karena itu pompa air dengan daya tinggi adalah solusi untuk menyelesaikan permasalahan yang ada saat ini dengan teknis untuk menyedot air dari sumber air yang berada dekat dari desa situraja dengan daya $4 \mathrm{KW}$ maka diharapkan permasalahan kekeringan dari sawah di desa situraja dapat diatasi dengan menciptakan jalan tengah dari permasalahan yang ada sehingga tidak menimbulkan perpecahan yang baru diantara masyarakat.

\section{b. Tujuan}

1. Merancang Desain Pompa air $4 \mathrm{KW}$

2. Memberikan solusi atas permasalahan pertanian yang ada di daerah persawahan Sawah Balong Desa Situraja Utara.

\section{c. Manfaat}

1. Meredakan konflik sosial yang disebabkan oleh penggantian shift pembukaan air untuk sawah karena debit air yang kecil pada irigasi sawah.

2. Memberikan exposure mengenai permasalahan di masyarakat bagi penggagas selaku mahasiswa.

3. Menciptakan desain alat Pompa berdaya $4 \mathrm{KW}$.

\section{Metode}

Metode yang digunakan pertama adalah studi pustaka dengan mencari sumber dari berbagai web perpustakaan artikel ilmiah untuk mencari permasalahan yang serupa 
dengan permasalahan. Selanjutnya metode yang digunakan observasi dari permasalahan yang sedang dihadapi, dalam kasus ini mengobservasi tempat terjadi nya permasalahan, yakni berupa sawah di daerah persawahan Sawah balong kabupaten Sumedang, setelah mendapatkan beberapa parameter dari data awal ini akan dirancang alat untuk memberi solusi atas masalah yang terjadi berdasarkan parameter yang telah ditentukan.

Langkah strategis perlu dilakukan direncanakan dengan matang agar gagasan ini dapat terealisasikan dengan baik, yaitu :

- Tahap 1 : Observasi untuk mencari sumber air untuk diambil dan alirkan ke daerah persawahan.

- Tahap 2 : Memberitahukan ide gagasan kepada produsen PCB, produsen pompa, produsen solar panel, dan produsen microhydro agar dapat menjadi solusi agrikultur yang baru.

- Tahap 3 : Meningkatkan kerja sama antara produsen dan penggagas karena agar terciptanya pengerjaan yang efisien dan sesuai dengan ide penggagas.

- Tahap 4 : Mengkoordinasikan pihak yang terlibat dan merealisasikan gagasan ini.

- Tahap 5 : Memonitor, dan mengevaluasi hasil pekerjaan yang telah dilaksanakan dalam mewujudkan gagasan agar terciptanya alat yang sesuai gagasan dengan kualitas dan keandalan yang terjamin dan bagus.

\section{Hasil dan Pembahasan}

Setelah melakukan observasi ke daerah persawahan Sawah Balong peneliti mendapati bahwa debit air pada saluran irigasi sangat rendah ketika musim kemarau tiba bisa dilihat dalam gambar berikut.

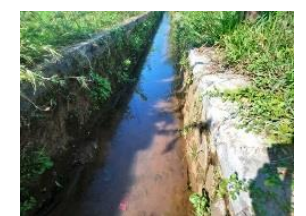

Gambar 1. Saluran Irigasi pada musim kemarau

Setelah ditelusuri hal ini disebabkan karena air yang tersedia di sumber air yaitu daerah Cibungur di Kecamatan Situraja berkurang.

Setalah melakukan studi pustaka menemukan solusi yang pernah ditawarkan untuk menyelesaikan permasalahan yang sama adalah irrigation management, yaitu dengan mengubah sistem pengairan sawah menjadi terasering yaitu air dari sawah sebelumnya mengalir ke sawah yang berada dibawahnya dengan ini tiap sawah akan mendapatkan sisa air dari sawah yang berada diatasnya. Namun hal ini tidak bisa dilakukan karena daerah perawahan Sawah Balong didominasi dataran yang rata sehingga tidak semua sawah dapat terairi.

Karena Irrigation management diimplementasian tidak dapat solusi yang paling tepat adalah dengan menambah debit air dari sumber yang lain. Ada beberapa sumber air yang lain yang memungkinkan untuk menambah debit air yang berada dekat dengan daerah perswahan sawah balong,

Tabel 1. Jarak Sumber Air

\begin{tabular}{|l|l|}
\hline Sumber air & \multicolumn{1}{|c|}{ Jarak } \\
\hline $\begin{array}{l}\text { Bendungan } \\
\text { Domas }\end{array}$ & $<3 \mathrm{Km}$ \\
\hline $\begin{array}{l}\text { Sungai } \\
\text { Cigodeg }\end{array}$ & $<1 \mathrm{Km}$ \\
\hline
\end{tabular}

Setalah menumukan sumber air maka yang diperlukan adalah merancang sebuah sistem pompa yang memompa air dari sumber air untuk meningkatkan debit air. Kerangka konseptual rancangan ini adalah merancang sistem pompa air dengan daya $4 \mathrm{KW}$ dengan minimal debit air $7.2 \mathrm{~m}^{3} / \mathrm{ha}$ dengan menggunakan mosfet sebagai driver 
utamanya. Sistem pompa memiliki spesifikasi

a. Berdaya $4 \mathrm{Kw}$

b. Alat harus tahan terhadap suhu hingga $57,74^{\circ} \mathrm{C}$

c. Alat harus tahan terhadap kelembaban

d. Alat harus tahan terhadap getaran

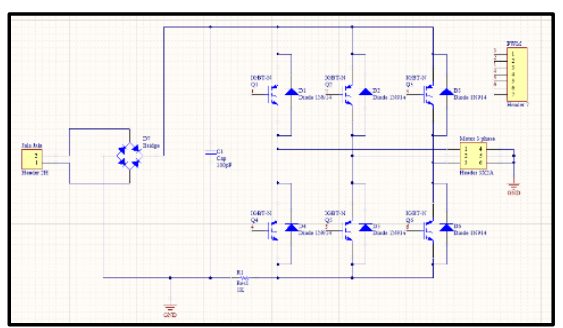

Gambar 2. Rangkaian driver

Hasil pengujian driver motor pada simulator proteus :

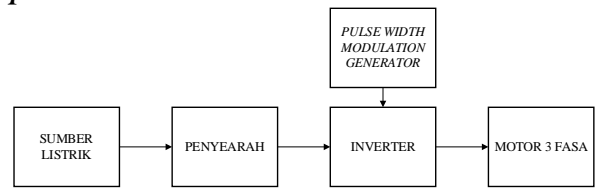

Gambar 3. Blok diagram driver

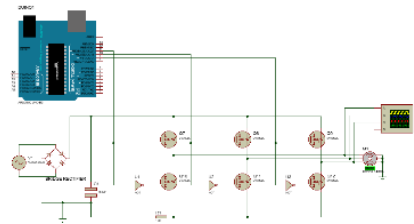

Gambar 4. Rangkaian Pengujian

Tabel 2. Perhitungan Daya Motor

\begin{tabular}{|l|c|}
\hline \multicolumn{2}{|c|}{ Motor 3 Phasa } \\
\hline Arus (A) & $0-58 \mathrm{~A}$ \\
\hline $\begin{array}{l}\text { Tegangan } \\
\text { (V) }\end{array}$ & 289 \\
\hline RPM & 1200 \\
\hline
\end{tabular}

Setelah dilakukannya percobaan melakukan simulator proteus didapatkan arus maksimum yang dipasok ke motor sebesar 58

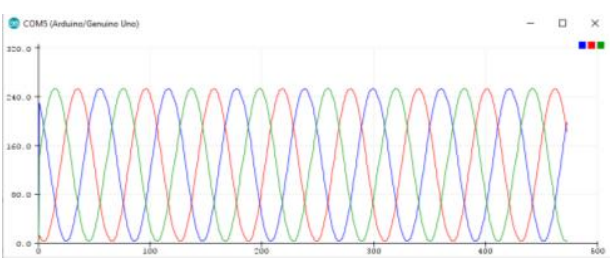

Gambar 5. Gelombang yang dihasilkan

A dan tegangan maksimal yang dipasok ke motor sebesar $289 \mathrm{~V}$ berdasarkan perhitungan Daya maka $\mathrm{P}=\mathrm{V}$. I $\mathrm{P}=289 \mathrm{~V} .58 \mathrm{~A}=16.7 \mathrm{KW}$

Maka driver yang dirancang dapat memasok motor sebesar $4 \mathrm{KW}$ dan kerja driver ada dibawah rating kerja sehingga motor akan lebih lama terpakai, dan ini akan memenuhi target yang akan dicapai yakni motor akan lebih lama terpakai karena driver yang menjalankan motor dapat berjalan dibawah rating daya yang tersedia di spesifikasi.

Sistem pompa sendiri dapat diatur kecepatanya sehingga dapat diatur sesuai kebutuhan. Ketika debit air berada pada kondisi minimal maka pompa dapat diatur pada kondisi penuh. Ketika debit menurun dan perlu ditingkatkan maka dapat diatur sesuai kebutuhan.

Sumber energi untuk menggerakan pompa berasal dari 3 sumber, jala - jala PLN sebagai sumber energi utama dengan daya yang paling besar. Kemudian ada pembangkit listrik tenaga microhidro yang dapat digunakan sebagai tambahan karena sumber air berupa sungai. Solar panel menjadi sumber energi yang ketiga, dengan menggunakan cahaya matahari solar panel dapat menambah cadangan energi untuk menggerakan sistem pompa. 
Blok Diagram :

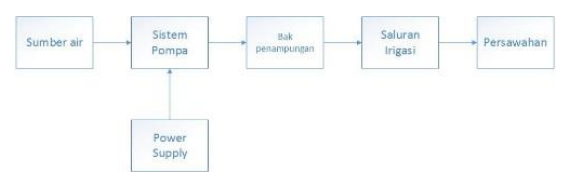

Gambar 6.Blok diagram solusi

Pompa memiliki fungsi untuk memompa air dari sumber air menuju bak penampungan. Air dari bak penampungan akan dialiarkan menuju saluran irigasi.

Setelah melakukan perancangan sistem pompa maka langkah selanjutnya adalah melakukan sosialisasi ke masyarakat di daerah persawahan Sawah Balong. Kemudian pengajuan program ke pemerintah Desa Situraja Utara. Dengan anggran mencapai 702 juta rupiah pertahun maka program ini cukup realistis. Setelah disetujui, Pemerintah akan melakukan kerjasama terhadap pihak terkait. Untuk realisasi masyarakat dan pemerintah bekerjasama dalam membangun sistem pompa. Setelah selesai langkah selanjutnya adalah melakukan monitoring.

\section{Kesimpulan}

Dari hasil penelitian yang dilakukan maka dapat disimpulkan bahwa:

- Penelitian ini berhasil merancang sebuah driver motor 3 phasa yang akan digunakan untuk pengadaan Pompa air berdaya $4 \mathrm{KW}$ untuk pengairan sawah di persawahan sawah balong

- Hasil pengujian menunjukan bahwa daya keluaran dari driver ini sekitar 16KW.

- Pengadaan pompa air dapat direalisasikan dengan adanya dana bantuan pada desa situraja utara sebesar 732 Juta per tahunnya.

- Pihak yang dapat merealisasikan Gagasan ini diantaranya adalah produsen energi seperti PLN dan PLTA, serta produsen pompa air.

\section{Ucapan Terimakasih}

Kami selaku tim peneliti mengucapkan banyak terimaksih kepada DIPA POLBAN yang telah membiayai pkm inih dan juga kepada pembimbing Ibu Dianthika Puteri Andini, SST., M.Sc. yang telah membimbing kami dalam penelitian ini.

\section{DAFTAR PUSTAKA}

[1] P. Manimekalai, R. Harikumar and R. Rajasekaran, "H-Bridge inverter with Sinusiodal Pulse Width Modulation Technique using Unipolar Switching for PV Aplication," International Jurnal of Applied Engineering Research, 2015.

[2] R. Issa, "Three-Phase Induction Motor Stator Current Optimizatio," International Journal of Computer Applications, 2010.

[3] T. Haryani, W. Wardoyo and A. Hidayar, "PERENCANAAN PEMBANGKIT LISTRIK TENAGA MIKROHIDRO," Jurnal Hidroteknik, vol. V, pp. 75-82, 2015.

[4] S. 1. Kuo, "Half-Bridge Transistor Inverter for Dc Powe Conversion," IEEE Transactions On Industrial and Control Instrumentation, vol. XXI, pp. 249-253, 1974.

[5] B. P. Hari, Jatmiko, M. Alimul and I. F. Huda, "EFISIENSI PENGGUNAAN PANEL SURYA SEBAGAI SUMBER ENERGI ALTERNATIF," Jurnal Emitor, vol. XVIII, pp. 10-14.

[6] M. R. A. Cahyono, "Analisa Pemanfaatan Harmonisa Sebagai Sumber Energi Alternatif," Jurnal Teknik Elektro, vol. VII, pp. 161-168, 2018.

[7] Azmi, Khairul;Sara, Ira Devi;Syahrizal, "Desain dan Analisis Inverter Satu Fasa dengan Menggunakan Metode SPWM berbasis Arduino," Jurnal Online Teknik ELektro Vol. 2 No.4, vol. II, pp. 36-44, 2017. 
